Research Article

Novel paclitaxel-coated balloon angioplasty via single retrograde popliteal access for challenging superficial femoral artery and iliac

\section{artery lesions?}

\author{
Erdem Cetin ${ }^{1 *}$, Celal Selcuk Unal ${ }^{1}$, Aydın Keskin ${ }^{1}$ and Hakan \\ Kartal $^{2}$
}

${ }^{1}$ Karabuk University Education and Research Hospital, Department of Cardiovascular Surgery, Karabuk, Turkey

${ }^{2}$ Gulhane Education and Research Hospital, Department of Cardiovascular Surgery, Ankara, Turkey

\section{Summary}

Objectives: We report our results regarding the use of BioPath ${ }^{T M}$ paclitaxel-coated balloon catheters for superficial or distal external iliac artery revascularization via single retrograde popliteal access.

Methods: We included 105 prospective consecutive patients. Single retrograde popliteal access was achieved under ultrasound guidance with the patients laid prone. An over-the-wire atherectomy system was used if risk of distal embolization was high due to plaque intensity of the target lesion. A 4 to $7 \mathrm{~mm}$-diameter BioPath ${ }^{\text {TM }} 035$ balloon catheter was used for all lesions. Follow-up at 6th month included doppler ultrasound examination for patency.

Results: Seventy-two patients $(68.6 \%)$ had total SFA occlusion and 41 patients (39\%) had concomitant external iliac artery involvement, out of whom $31(29.5 \%)$ had total occlusion. Procedural success $90.5 \%$ for superficial femoral artery and $85.3 \%$ for external iliac artery. Oneyear patency rates in SFA and EIA were $84.8 \%$ and $80.4 \%$, respectively

Conclusion: Single retrograde popliteal access and drug-coated balloon angioplasty may offer a useful alternative to known modalities in treatment of challenging superficial femoral artery and concomitant iliac artery lesions.

\section{More Information}

*Address for Correspondence: Erdem Cetin, MD Department of Cardiovascular Surgery, Karabuk University Education and Research Hospital, Sirinevler Mah. Alparslan Cad. No: 1, Karabuk, Turkey, Tel: 05392905659; Email: opdrerdemcetin2018@gmail.com

Submitted: 09 September 2019

Approved: 23 September 2019

Published: 24 September 2019

How to cite this article: Cetin E, Unal CS, Keskin A, Kartal H. Novel paclitaxel-coated balloon angioplasty via single retrograde popliteal access for challenging superficial femoral artery and iliac artery lesions. J Cardiol Cardiovasc Med. 2019; 4: 140-143.

DOI: dx.doi.org/10.29328/journal.jccm. 1001055 ORCID ID: orcid.org/0000-0002-4065-9016

Copyright: @ 2019 Cetin E, et al. This is an open access article distributed under the Creative Commons Attribution License, which permits unrestricted use, distribution, and reproduction in any medium, provided the original work is properly cited

Keywords: Peripheral artery disease; Drug-coated balloon angioplasty; Retrograde access

Check for updates

\section{Introduction}

Lower extremity peripheral artery disease (PAD) reduces the quality of life and affects social life. Moreover, it is a major cause of cardiovascular mortality and morbidity in the elderly $[1,2]$. Data suggest that femoral-popliteal segment involvement is present about $70 \%$ of patients with symptomatic peripheral artery disease whereas aortoiliac disease is associated with a poorer prognosis $[3,4]$. There has been a recent trend towards endovascular revascularization of both aortoiliac and femoralpopliteal segment lesions even in the presence of chronic total occlusion. However, use of drug-eluting or self-expanded stents has been troublesome due to the risk of stent fracture.

Stent implantation to the superficial femoral artery (SFA) in its proximal half may become complicated due to the technical difficulty of deployment the proximal crown of the stent into a highly calcified SFA and profunda branch bifurcation, which compromises long term patency of the stent [5]. Drug coated balloons have recently attracted attention by eliminating these drawbacks of stent implantation to the lower extremity [6]. Recently, retrograde route of endovascular intervention to the SFA lesions via popliteal artery has gained attraction [7].

BioPath $^{\mathrm{TM}}$ is a novel drug eluted balloon device which contains shellac coating on the surface of its balloon to facilitate the pressure-induced delivery of Paclitaxel, a known antimitotic agent to inhibit vascular restenosis. We herein report our results regarding the use of BioPath ${ }^{\text {TM }} 035$ and 
BioPath $^{\mathrm{TM}} 014$ paclitaxel-coated balloon catheters during SFA or distal external iliac artery (EIA) revascularization via single retrograde popliteal access.

\section{Patients and Methods}

The study was approved by the institutional review board. This was a prospective cohort study which was conducted in a tertiary hospital between December 2017 - May 2018 and we included Fontaine stage II-IV symptomatic peripheral artery disease patients who underwent endovascular balloon revascularization for above the knee lesions through single retrograde popliteal access. Patients were included if use of the retrograde popliteal access was decided in advance and patients in whom route of access was switched from retrograde to antegrade during procedure were not included. Patients were excluded if retrograde popliteal access was inevitable due to lack of blood flow within popliteal artery. Patients with a history of several failed attempts with endovascular techniques or those having a clear contraindication for use of endovascular techniques were also excluded.

A total of 105 consecutive patients were included in the study. All patients had at least $80 \%$ involvement within the SFA whereas 41 patients (39.0\%) had concomitant > 80\% distal EIA involvement. Patient counseling charts, laboratory tests and angiography views (computed tomography or conventional angiography) were reviewed and recorded. Ankle-brachial index $(\mathrm{ABI})$ measurements were performed and recorded before the operation. Diabetic patients were consulted with endocrinologist and subcutaneous insulin therapy was initiated, as needed. Patients who continue smoking were referred for smoking cessation department before the operation. All patients were started on dual antiplatelet therapy with aspirin $100 \mathrm{mg}$ daily and clopidrogel $75 \mathrm{mg}$ daily on the same day of the procedure.

All procedures were performed in a fully equipped catheter laboratory and were completed under local anesthesia with the aid of C-arm fluoroscopy guidance. Standard monitoring included 12-lead electrocardiogram, pulse oximetry and non-invasive blood pressure monitoring. The patients were placed in prone position and the procedure was completed without switching to supine position. All patients received an intravenous bolus of unfractioned heparin (70 to $100 \mathrm{U} /$ $\mathrm{kg}$ ) immediately before initial retrograde popliteal access. A diagnostic angiography was performed to determine target locations using digital subtraction views, as necessary. Multiple short adjacent lesions were considered as a single target and balloon dilatation was performed according to the cumulative length. Retrograde popliteal access was achieved by puncturing the popliteal artery beneath popliteal fossa using a 19-G to 21-G puncture needle under ultrasound guidance. After insertion of a $4 \mathrm{~F}$ or $6 \mathrm{~F}$ sheath into the popliteal artery lumen, a translucent shafted support microcatheter ( 0.015 to 0.036 inch in diameter) was crossed first if SFA was totally occluded, as it was the case in majority of patients. Then a standard guide wire was introduced through its lumen and it was withdrawn. The SFA lesion was first pre-dilated with an uncoated balloon undersized to the target vessel. An over-the-wire atherectomy system which allows clearance of the debulked material from the lumen was used if risk of distal embolization was high due to plaque intensity of the target lesion. The BioPath ${ }^{\text {тM }}$ catheter was then introduced through the target SFA lesion and fixed $10 \mathrm{~mm}$ proximal and distal to the diseased segment. A 4 to $7 \mathrm{~mm}$-diameter BioPath ${ }^{\mathrm{TM}} 035$ balloon catheter was used for all lesions. The balloon was inflated at 6 bars for at least 120s and balloon catheter was withdrawn if angiographic result was satisfactory. In patients with concomitant distal EIA involvement, the same procedure was repeated using appropriately sized catheters. Procedural success was defined as at least $20 \%$ residual stenosis after completion of the procedure whereas patients with $<20 \%$ residual stenosis received stent implantation at the same session. The procedure was completed after closure of the puncture site with an Angio-Seal catheter. Cilostazol 100mg/d was started after the procedure and continued for 6 months. Aspirin $100 \mathrm{mg}$ daily was continued indefinitely whereas clopidrogel was continued for 3 months after the operation.

Ankle brachial index measurements were repeated 1 to 2 days after operation. Patients were invited to follow-up visits at 1 week, 1 to 2 months and 6 months after the operation. Followup assessments included doppler ultrasound examination for patency. Repeat angiography was not performed unless Doppler examination reveals diminished flow across the target lesion.

\section{Statistical analysis}

All analyses were performed using SPSS (Statistical Package for the Social Sciences) version 19.0. Continuous parameters were defined as mean \pm standard deviation and categorical parameters were defined as percentages. Normal distribution of the continuous parameters was evaluated using visual histograms and analytical methods (KolmogorovSmirnov or Shapiro-Wilk's test). Comparison of ABI values between preoperative and postoperative measurements were made using Wilcoxon Signed Ranks Test. A $p$ value of less than 0.05 was statistically significant.

\section{Results}

Baseline characteristics of the patients were given in table 1 . Mean age was $63.73 \pm 9.23$ years and $98(93.3 \%)$ of the patients were males. All patients had at least $80 \%$ SFA involvement, out of whom 72 (68.6\%) had total SFA occlusion. Forty-one patients (39\%) had concomitant distal EIA involvement, out of whom 31 (29.5\%) had total occlusion. Occluded segment was crossed with a support microcatheter in 93 patients $(88.6 \%)$ and pre-dilatation with an uncoated balloon catheter was performed in 61 patients $(58.1 \%)$. Catheter atherectomy was used in 19 patients (18.1\%). 
Table 1: Baseline characteristics.

\begin{tabular}{|c|c|}
\hline Variable & Mean \pm SD $/ \mathbf{n}(\%)$ \\
\hline Age (years) & $63.73 \pm 9.23$ \\
\hline Males & $98(93.3 \%)$ \\
\hline Hypertension & $70(66.7 \%)$ \\
\hline Diabetes & $43(41.0 \%)$ \\
\hline Dyslipidemia & $48(45.7 \%)$ \\
\hline Tobacco use & $89(84.8 \%)$ \\
\hline Family history & $73(69.5 \%)$ \\
\hline
\end{tabular}

Procedural success for SFA lesions was achieved in 95 patients $(90.5 \%)$ whereas drug coated balloon did not result in adequate expansion of the target arterial segment in the remaining. Four of these failed procedures was due to the extreme stiffness of the arterial wall despite successful removal of excessive plaques with catheter atherectomy whereas SFA was hypoplastic and thin and catheter atherectomy was not attempted in 6 patients.

Procedural success was achieved in 35 of 41 patients (85.3\%) with concomitant distal EIA involvement. In four patients, complete distal EIA occlusion could not be treated with atherectomy device due to failed SFA recanalization. In 2 patients, atherectomy was successful but drug coated balloon could not dilate the diseased segment enough because of extreme stiffness.

After the procedure, mean ABI values showed a significant increase from $0.42 \pm 0.21$ to $0.85 \pm 0.27(p<0.001)$ and number of patients with an ABI $>80 \%$ significantly increased from 5 $(4.8 \%)$ to $76(72.4 \%)(p<0.001)$. One-year patency rates in SFA and EIA were $84.8 \%$ and $80.4 \%$, respectively (Table 2).

\section{Discussion}

Our study demonstrated that drug-coated balloon angioplasty with Biopath ${ }^{\mathrm{TM}}$ device via single retrograde popliteal access produced acceptable procedural success and satisfactory 1-year patency for treatment of challenging SFA and distal EIA lesions. In our study, about two-third of SFA lesions and one third of EIA lesions were total occlusions and most of the remaining lesions were long segmented near-total occlusions. Concomitant use of assistive devices including supporting micro-catheter, uncoated

\begin{tabular}{|c|c|}
\hline Table 2: Study outcomes. & \\
\hline Variable & Mean \pm SD / n (\%) \\
\hline Use of microcatheter & $93(88.6 \%)$ \\
\hline Uncoated balloon angioplasty & $61(58.1 \%)$ \\
\hline Drug-coated balloon angioplasty & $89(84.8 \%)$ \\
\hline Atherectomy catheter & $19(18.1 \%)$ \\
\hline SFA success & $95(90.5 \%)$ \\
\hline Iliac success & $35(85.3 \%)$ \\
\hline Amputation & $2(1.9 \%)$ \\
\hline Surgery & $9(8.6 \%)$ \\
\hline Ankle brachial index (Preoperative vs. Postoperative) & $0.42 \pm 0.21$ vs. $0.85 \pm 0.27^{\text {a }}$ \\
\hline ABI $\geq 80 \%$ (Preoperative $v s$. Postoperative) & $5(4.8 \%) v s .76(72.4 \%)$ \\
\hline 1-year patency in SFA & $89 / 105(84.8 \%)$ \\
\hline 1-year patency in iliac artery & $33 / 41(80.4 \%)$ \\
\hline ap $<0.001$ for Wilcoxon Signed Rank Test \\
\hline
\end{tabular}

balloon and atherectomy devices allowed us to cross these lesions and achieve satisfactory angiographic results in about $90 \%$ of the patients.

Our results revealed that crossing the challenging SFA lesions through a single retrograde popliteal access without any additional antegrade recanalization was possible in about $90 \%$ of the patients and this also allowed us crossing the concomitant lesions in distal EIA in $85.3 \%$ of our patients. Balloon dilatation with drug-coated Biopath ${ }^{\mathrm{TM}}$ device eliminated the need for implantation of a stent and produced a one-year patency rate that is comparable to those reported in previous studies using various stent devices.

Retrograde approach for SFA occlusion has recently gained popularity. Some authors reported the use of retrograde approach as a salvage alternative particularly when the antegrade route was unsuccessful. Pappy, et al. [8], reported in their case series of 4 patients in which retrograde approach achieved successful SFA stent recanalization following their failed attempts with antegrade route. In a larger scale study, Sangiorgi, et al. [9], used the retrograde approach as a bailout strategy in 23 (25 limbs) of a total of 130 patients with SFA occlusions. In this study, 13 of 23 patients received stent implantation and the remaining had adequate patency with balloon dilatation. The authors reported that retrograde approach achieved higher procedural success rates compared to antegrade approach ( $95.7 \%$ vs. $86.0 \%$ for retrograde and antegrade access, respectively) and they reported similar one-year patency rates $(80 \%$ vs. $86 \%$ for standard access and retrograde access, respectively, $p=0.78$ ) this effect was not counterbalanced by increased risk of complications.

Ye, et al. [10] used the retrograde access in 19 of 213 patients who had challenging SFA occlusions. The authors performed retrograde subintimal tracking to re-enter to the proximal lumen and they completed the procedure via dualchannel intervention (antegrade + retrograde). Fourteen out of these 19 patients achieved adequate patency with balloon dilatation only and the authors reported a 6-month patency rate of $84.2 \%$. Similarly, Shi, et al. [11], used a dual antegraderetrograde approach in 21 patients and they achieved successful stent implantation in all patients. Although 6-month patency was $80 \%$ in this study, the one-year patency rate was as low as $42 \%$.

Tokuda, et al. [12] reported on 68 patients in whom they switched from antegrade access to retrograde access during endovascular balloon + stent angioplasty for long-segment occluded SFA lesions. The procedural outcomes of the study were compared between patients receiving or not receiving sheath insertion during retrograde access. Although the study reported no follow-up patency rate, the procedure was completed with a success rate of $89.8 \%$ and with very low complication rates in patients whom a sheath was not needed at all during the procedure. 
Although, there have been some reports on use of the retrograde technique almost routinely as a facilitating adjunct to antegrade femoral access [13-16], its use as a sole rather than an alternative or adjunctive to antegrade technique is rare. In one study where primary success of intervention was compared between patients receiving antegrade ( $\mathrm{n}=$ 55 patients) $v s$. retrograde $(\mathrm{n}=36$ patients) approach, the decision for performing retrograde access was made in advance in all but three patients in the retrograde group [17]. In this study, after initial retrograde access was performed in the prone position, the patient was placed in the supine position and the procedure was continued. The authors reported that the procedural success rate was significantly higher in the retrograde access group $(97.2 \%$ vs. $78.2 \%$, respectively; $p<0.01$ ) with acceptable morbidity rates (5 minor complication and 1 major bleeding). Dumantepe, et al. [18], used the retrograde technique as the primary choice in 28 patients, performed the initial popliteal puncture in the prone position while guided by duplex ultrasound and continued the procedure in the prone position. From a technical point of view, the authors report that they pass total occlusion using an atherectomy catheter through a sheath and insert nitinol vowen stent after balloon dilatation. One-year patency was reported to be $85.7 \%$.

The main limitation of the present study was that there was no control group to test the effect of the technique used on study outcomes. The technique we described here has become our standard of care in recent years and we thought it was inappropriate to use a technique we abandoned for construction of a control group. In conclusion, single retrograde popliteal access and drug-coated balloon angioplasty may offer a useful alternative to known modalities in treatment of challenging SFA and concomitant iliac artery lesions.

\section{References}

1. Aragão JA, Santos RM, Neves OMG, Aragão ICS, Aragão FMS, et al. Quality of life in patients with peripheral artery disease. J Vasc Bras. 2018; 17: 117-121.

PubMed: https://www.ncbi.nlm.nih.gov/pubmed/30377420

2. Conte SM, Vale PR. Peripheral Arterial Disease. Heart Lung Circ. 2018; 27: 427-432.

PubMed: https://www.ncbi.nlm.nih.gov/pubmed/29150158

3. Aboyans V, Desormais I, Lacroix P, Salazar J, Criqui MH, et al. The genera prognosis of patients with peripheral arterial disease differs according to the disease localization. J Am Coll Cardiol. 2010; 55: 898-903. PubMed: https://www.ncbi.nlm.nih.gov/pubmed/20185041

4. Kalbaugh CA, Kucharska-Newton A, Wruck L, Lund JL, Selvin E, et al. Peripheral Artery Disease Prevalence and Incidence Estimated From Both Outpatient and Inpatient Settings Among Medicare Feefor-Service Beneficiaries in the Atherosclerosis Risk in Communities (ARIC) Study. J Am Heart Assoc. 2017; 6: e003796.

PubMed: https://www.ncbi.nlm.nih.gov/pubmed/28468784

5. Yamawaki M, Hirano K, Nakano M, Sakamoto $\mathrm{Y}$, Takimura $\mathrm{H}$, et al. Deployment of self-expandable stent for complex proximal superficial femoral artery lesions involving the femoral bifurcation with or without jailed deep femoral artery. Catheter Cardiovasc Interv. 2013; 81: 1031 1041.
PubMed: https://www.ncbi.nlm.nih.gov/pubmed/22639451

6. Werner M. Angioplasty with drug coated balloons for the treatment of infrainguinal peripheral artery disease. Vasa. 2016; 45: 365-372. PubMed: https://www.ncbi.nlm.nih.gov/pubmed/27351416

7. Olinic DM, Spinu M, Olinic M, Homorodean C, Tataru DA, et al Epidemiology of peripheral artery disease in Europe: VAS Educational Paper. Int Angiol. 2018; 37: 327-334.

PubMed: https://www.ncbi.nlm.nih.gov/pubmed/29936722

8. Pappy R, Hennebry TA, Abu-fadel MS. Retrograde access via the popliteal artery to facilitate the re-entry technique for recalcitrant superficial femoral artery chronic total occlusions. Catheter Cardiovasc Interv. 2011; 78: 625-631.

PubMed: https://www.ncbi.nlm.nih.gov/pubmed/21648050

9. Sangiorgi G, Lauria G, Airoldi F, Godino C, Politi L, et al. Retrograde popliteal access as bail-out strategy for challenging occlusions of the superficial femoral artery: a multicenter registry. Catheter Cardiovasc Interv. 2012; 79: 1188-1193.

PubMed: https://www.ncbi.nlm.nih.gov/pubmed/22234869

10. Ye $M$, Zhang $H$, Huang $X$, Shi $Y, Y a o$, et al. Retrograde popliteal approach for challenging occlusions of the femoral-popliteal arteries. J Vasc Surg. 2013; 58: 84-89.

PubMed: https://www.ncbi.nlm.nih.gov/pubmed/23806253

11. Shi W, Yao Y, Wang W, Yu B, Wang S, et al. Combined antegrade femoral artery and retrograde popliteal artery recanalization for chronic occlusions of the superficial femoral artery. J Vasc Interv Radiol. 2014; 25: 1363-1368.

PubMed: https://www.ncbi.nlm.nih.gov/pubmed/24657086

12. Tokuda T, Hirano K, Muramatsu T, Tsukahara R, Nakano M. A sheathless retrograde approach via the popliteal artery is useful and safe for treating chronic total occlusions in the superficial femoral artery. J Endovasc Ther. 2014; 21: 289-295.

PubMed: https://www.ncbi.nlm.nih.gov/pubmed/24754289

13. Matsumi J, Takada T, Moriyama N, Ochiai T, Tobita K, et al. Initial and Long-Term Results of a Microcatheter-Based Retrograde Approach for the Endovascular Treatment of Chronic Total Occlusion in Iliac or Femoropopliteal Arteries. Ann Vasc Surg. 2017; 41: 176-185. PubMed: https://www.ncbi.nlm.nih.gov/pubmed/28238927

14. Ruzsa Z, Wojtasik-Bakalarz J, Nyerges A, Rakowski T, Kleczynski P, et al. Long-Term Follow-up After Retrograde Recanalization of Superficial Femoral Artery Chronic Total Occlusion. J Invasive Cardiol. 2017; 29: 336-339.

PubMed: https://www.ncbi.nlm.nih.gov/pubmed/28974660

15. Wojtasik-Bakalarz J, Arif S, Chyrchel M, Rakowski T, Bartuś K, et al. Twelve months follow-up after retrograde recanalization of superficial femoral artery chronic total occlusion. Postepy Kardiol Interwencyjnej. 2017; 13: 47-52.

PubMed: https://www.ncbi.nlm.nih.gov/pubmed/28344617

16. Palena LM, Diaz-sandoval LJ, Raja LM, Morelli L, Manzi M. Precise Retrograde Supera Stenting of the Ostium (PRESTO) of the Superficial Femoral Artery for Complex Femoropopliteal Occlusions: The PRESTO Technique. J Endovasc Ther. 2018; 25: 588-591.

PubMed: https://www.ncbi.nlm.nih.gov/pubmed/29363382

17. Ueshima D, Ashikaga T, Shimura T, Hatano Y, Sasaoka T, et al. Popliteal Retrograde Approach is Effective and Safe for Superficial Femoral Artery Chronic Total Occlusion. Ann Vasc Dis. 2015; 8: 220-226. PubMed: https://www.ncbi.nlm.nih.gov/pubmed/26421071

18. Dumantepe M. Retrograde Popliteal Access to Percutaneous Peripheral Intervention for Chronic Total Occlusion of Superficial Femoral Arteries. Vasc Endovascular Surg. 2017; 51: 240-246.

PubMed: https://www.ncbi.nlm.nih.gov/pubmed/28595481 